\section{nephron}

Practice
Nephron 2017;136:277-280

DOI: $10.1159 / 000448183$
Received: March 13, 2016

Accepted after revision: July 2, 2016

Published online: December 16, 2016

\title{
The Hyperfiltering Kidney in Diabetes
}

\author{
Roberto Trevisan Alessandro Roberto Dodesini \\ USC Malattie Endocrine - Diabetologia, ASST Papa Giovanni XXIII, Bergamo, Italy
}

\section{Key Words}

Hyperfiltration · Diabetes · Intraglomerular pressure ·

Diabetic nephropathy

\section{Abstract}

Hyperfiltering kidney is a typical feature of diabetes. Improvement observed with regard to glucose control and blood pressure control reduces the high glomerular filtration rate and may contribute to retard the appearance and the progression of diabetic renal disease. Although the mechanism of hyperfiltration is still unclear, there is mounting evidence that the increased reabsorption of glucose and sodium by sodium glucose transporter-2 (SGLT-2) is involved in this altered renal function. There is a possibility that SGLT-2 inhibition may correct hyperfiltration in diabetes, adding a new therapeutic approach to halt renal disease in patients with diabetes.

(c) 2016 S. Karger AG, Basel

\section{Hyperfiltration, a Typical Feature of Diabetes in Humans}

An increased glomerular filtration rate (GFR) is a typical feature of type 1 diabetic patients of short duration and it is also observed in type 2 diabetic patients. Although early elevation of the GFR plays a central role in the pathogenesis and progression of renal disease in experimental diabetes [1], a clear evidence that glomerular hyperfiltration may contribute to the progression of kidney disease in humans is still lacking. Small cohort studies

\section{KARGER}

(C) 2016 S. Karger AG, Basel

E-Mail karger@karger.com

www.karger.com/nef found that types 1 and 2 diabetes subjects with glomerular hyperfiltration tended to be at increased risk of microalbuminuria, taken as an early marker of nephropathy [2]. Some studies found an accelerated renal function loss in hyperfiltering patients compared to those with normal or reduced GFR [2], but these findings were not confirmed in other series [3]. However, whether hyperfiltration affected the rate of GFR decline and predicted microalbuminuria independent of blood pressure and metabolic control has never been formally addressed in adequately powered studies. Moreover, reported prevalence of hyperfiltration varied widely from series to series due to different definitions, methods for GFR evaluation and patient's characteristics.

\section{Hyperfiltration: Definition and Mechanisms}

In defining hyperfiltration, GFR can be treated as a continuous or dichotomous variable. However, hyperfiltration has been traditionally defined as GFR $>2$ standard deviations above the mean GFR in control participants. According to various studies, the threshold for hyperfiltration has ranged from 120 to $140 \mathrm{ml} / \mathrm{min} / 1.73 \mathrm{~m}^{2}[4,5]$.

Using precise measurements (renal clearance of inulin, iothalamate, $\mathrm{Cr}^{51}$-EDTA or ioexol) the mean GFR has been found to be increased by $15-25 \%$ in type 1 diabetic patients of short duration [6]. The evidence that hyper-

Contribution from the CME course of the DIABESITY Working Group of the ERA-EDTA, Bergamo, December 4-5, 2015.

Dr. Roberto Trevisan

USC Malattie Endocrine - Diabetologia

ASST Papa Giovanni XXIII

IT-24100 Bergamo (Italy)

E-Mail rtrevisan@asst-pg23.it 
glycemia was related to hyperfiltration was confirmed by the reduction of GFR after improvement of glucose control in type 1 diabetic patients [7]. However, glomerular hyperfiltration remains a characteristic feature of kidney function for the first one or 2 decades of diabetes duration, even in type 1 diabetic patients with microalbuminuria [8].

The larger increase in GFR than renal plasma flow (RPF) with increased filtration fraction suggests intraglomerular hypertension as an important factor in hyperfiltration [9]. The pathophysiological mechanism behind the increased GFR and RPF are still unclear. The renal autoregulation of GRF, in normal conditions, is provided by a myogenic mechanism and by tubule-glomerular feedback. With the myogenic mechanism, an increase in blood pressure stretches afferent arteriole in the glomerulus with a consequent arteriole constriction, which eventually leads to a restoration of normal GFR. At the same time, macula densa on distal tubule monitors tubular fluid and signals juxtaglomerular cells (smooth muscle, surrounds afferent arteriole) to constrict afferent arteriole to decrease GFR (tubulo-glomerular feedback).

It is important to note that total renal filtration (that is GFR) is affected by single nephron GFR and by the number of functioning glomeruli. Thus, when the number of functioning glomeruli is substantially decreased, the total GFR may be within the normal range or may even be decreased despite single glomerular hyperfiltration (this may be the case in older patients with type 2 diabetes). When the number of functioning nephrons is substantially reduced, hyperfiltration of residual functioning glomeruli may be further amplified by adaptive mechanisms (additional to those related to the tubular glomerular feedback) that are aimed at sustaining total GFR despite decreased nephron mass. This is a crucial issue, because hyperfiltration may contribute to the pathogenesis and progression of diabetic kidney disease and amelioration of glomerular hyperfiltration may be renoprotective even when total GFR is in the normal range or decreased [1].

Based mainly on experiments in rodent models, glomerular and tubular theories have been advanced for the development of hyperfiltration in diabetes [9]. There is no doubt, however, that hyperglycemia plays a key role in glomerular hyperfiltration. Under chronic hyperglycemic conditions, the increased proximal glucose reabsorption by sodium glucose transporter-2 (SGLT-2) mediates the reabsorption of sodium and glucose and impairs the normal tubulo-glomerular feedback mechanism. This impairment leads to inadequate arteriole tone and increased renal perfusion [10].
Another point to be noted is that hyperfiltration in diabetes is associated with nephromegaly [11]. One of the earliest structural changes in the diabetic kidney is the hypertrophy and hyperplasia of the cortical tubuli and concomitant renal enlargement. Although there is an increase in glomerular volume, most of the increase in cortical mass may be accounted for by hypertrophy of the proximal tubule. It had been suggested that tubular glucose reabsorption associated with hyperglycemia is a dominant driving force, leading to increased expression of growth factors like transforming growth factor $\beta$, vascular endothelial growth factor and insulin-like growth factor. In support, studies with the nonspecific SGLT inhibitor, phlorizin, and more recently with selective SGLT-2 inhibitor, empaglifozin, have shown that the inhibition of glucose reabsorption was able to attenuate renal hypertrophy associated with experimental diabetes [12].

There is also a growing body of data suggesting that obesity-related glomerulopathy associated with ectopic lipid accumulation in the kidney may contribute substantially to nephromegaly and hyperfiltration independently of hyperglycemia [13].

Whether renal hypertrophy is a predictor of renal disease progression in subject with diabetes is still unclear.

\section{Hyperfiltration in Type 2 Diabetic Patients: Relation with Renal Disease Progression}

Contrary to type 1 diabetes, the existence and prevalence of hyperfiltration in type 2 diabetes have presented contrasting reports. In several small studies from different groups, the prevalence of high GFR has varied from 0 to $45 \%$ in recently diagnosed patients [4]. The most likely factors responsible for the marked variability of these estimates are age, glycemic control, duration of diabetes and the method used for expressing GFR in obese patients.

In a well-conducted study including 194 Pima Indians with different stages of glucose tolerance, GFR was elevated at the onset of diabetes and remained so even at the microalbuminiuria stage. It declines progressively only after the development of macroalbuminuria. In this study, it is of note that GFR was already higher in patients with impaired glucose tolerance than in normal controls, suggesting the possibility that hyperfiltration may even precede the onset of diabetes. This finding strengthens the role of other factors beyond hyperglycemia, such as obesity and/or insulin resistance in affecting glomerular hemodynamics [14].
Trevisan/Dodesini 
In the non-diabetic population, there is an age-related annual decrease in GFR of $1 \mathrm{ml} / \mathrm{min} / 1.73 \mathrm{~m}^{2}$ after the age of 40 years. In older patients with type 2 diabetes, hyperfiltration can be masked by this age-related decline in GFR. In a clinic-based cross-sectional study of 662 patients with type 2 diabetes, the overall prevalence of hyperfiltration was $7.4 \%$ without age correction and $16.6 \%$ after adjustment for age [15].

A recent prospective observational long-term (median follow-up: 4 years) study evaluated GFR decline and renal disease progression in 600 type 2 diabetic patients with normo- or microalbuminuria identified from the outpatient clinics of our Diabetology Unit and other Diabetology Units in Italy and Slovenia. These patients were included in 2 trials conducted in cooperation with the IRCCS - Istituto di Ricerche Farmacologiche Mario Negri, which aimed to test the renoprotective effect of trandolapril or delapril in addition to intensified metabolic $\left(\mathrm{HbA}_{1 \mathrm{C}}<7 \%\right)$ and blood pressure $(<120 / 80 \mathrm{~mm} \mathrm{Hg})$ control [5]. GFR was measured by ioexol e.v. every 6 months and the rate of GFR decline over time (GFR slope) was defined as the regression line between repeated GFR measurements and time. Patients who had a measured GFR at inclusion exceeding the upper limit of the normal range $\left(120 \mathrm{ml} / \mathrm{min} / 1.73 \mathrm{~m}^{2}\right)$ were a priori categorized as 'hyperfiltering'.

Ninety patients ( $15 \%$ of the study population) were hyperfiltering at inclusion.

Despite intensified therapy for blood pressure and glucose control, long-term GFR decline averaged $3 \mathrm{ml} / \mathrm{min} / 1.73 \mathrm{~m}^{2}$ per year, a decline $3-5$ folds faster than that reported in the general population. Moreover, it was observed that more GFR reduction at 6 months predicted slower GFR decline on follow-up, independently of concomitant therapy with ACE inhibitors and level of initial albuminuria, whereas long-term GFR decline and progression to micro or macroalbuminuria were faster in subjects with persistent hyperfiltration as compared to non-hyperfiltering subjects and to those who had their hyperfiltration at inclusion ameliorated by intensified BP and metabolic control on follow-up.

The above differences in disease outcomes were associated with less effective blood pressure and metabolic control in those with persistent hyperfiltration, despite similar patterns of treatment in patients with or without persistent hyperfiltration.

In conclusion, this study in a large cohort of type diabetic patients showed that persistent glomerular hyperfiltration is an independent predictor of accelerated GFR decline and progression to micro- or macroalbuminuria,

Hyperfiltration and Diabetic Kidney Disease whereas amelioration of hyperfiltration appeared to be renoprotective. Although this was one of the largest and longer studies on GFR in type 2 diabetes, ad hoc studies are needed to assess whether glomerular hyperfiltration can be a specific target for renoprotective intervention.

\section{Hyperfiltration: A Possible Therapeutic Role for SGLT-2 Inhibitors}

The recent introduction of novel agents to inhibit SGLT-2 as a means to improve glucose controls has shown the potential for direct renoprotective action.

In a recent and elegant mechanistic study, Cherney et al. [16] have evaluated the effect of empaglifozin, an SGLT-2 inhibitor, on renal hyperfiltration in type 1 diabetic patients. Both during clamped eu- and hyperglycemia, they found that hyperfiltration was attenuated after empaglifozin treatment and this effect was accompanied by declines in NO and effective RPF and an increased renal vascular resistance. This particular pattern of renal hemodynamic function change was compatible with preglomerular vasoconstriction. In contrast, renal hemodynamic parameters remained unchanged in type 1 diabetic subjects with normal GFR, suggesting that tubule-glomerular feedback does not contribute significantly to the regulation of renal function in these individuals. Furthermore, by using the Gomez equations [17] to estimate glomerular hemodynamic function, the same group was able to demonstrate that hyperfiltering type 1 diabetic patients exhibited afferent vasodilation with a lower vascular resistance [18]. Moreover, empaglifozin treatment was able to increase vascular resistance of afferent arteriole and also reduce intraglomerulare pressure, with no effect on the resistance of the efferent arteriole.

The authors suggested that reducing pre- and postglomerular resistances with SGLT-2 inhibitors and RAS inhibitors, respectively, may synergistically contribute to reduce intraglomerular pressure, an effect that is expected to translate into more effective long-term renoprotection with combination therapy than with SGLT-2 and RAS inhibition monotherapy.

Although this renoprotective effect needs to be confirmed by controlled trials, the recent data form EMPA-REG OUTCOME trial showed that in patients with type 2 diabetes at high cardiovascular risk (the majority already treated with RAS inhibitors), empaglifozin was associated were a slower progression of kidney disease and lower rates of clinically relevant renal events than was placebo when added to the standard care [19].

Nephron 2017;136:277-280 


\section{Conclusions}

Hyperfiltration is a typical feature of type 1 diabetic patients and type 2 diabetic patients. Although hyperglycemia is clearly involved in this hemodynamic abnormality, there is also increasing evidence that other factors such as obesity, insulin resistance and other metabolic factors associated with the metabolic syndrome may contribute both to hyperfiltration and nephromegaly.

Several clinical studies suggested a possible role of hyperfiltration as a causative factor in renal disease progression, although ad hoc studies are needed to assess wheth- er glomerular hyperfiltration can be a specific target for renoprotective intervention.

Therapy with SGLT-2 inhibitors may correct hyperfiltration in diabetes and a recent clinical trial showed that they may contribute to reduce the progression of renal disease in type 2 diabetic patients.

\section{Disclosure Statement}

R.T. has received speaking and/or consulting fees from AstraZeneca, Boehringer Ingelheim, Eli Lilly, Novo Nordisk, Janssen and Merck. A.R.D. declares no potential conflicts of interest relevant to this article.

\section{References}

1 Zatz R, Dunn BR, Meyer TW, Anderson S, Rennke HG, Brenner BM: Prevention of diabetic glomerulopathy by pharmacological amelioration of glomerular capillary hypertension. J Clin Invest 1986;77:1925-1930.

2 Magee GM, Bilous RW, Cardwell CR, Hunter SJ, Kee F, Fogarty DG: Is hyperfiltration associated with the future risk of developing diabetic nephropathy? A meta-analysis. Diabetologia 2009;52:691-697.

3 Ficociello LH, Perkins BA, Roshan B, Weinberg JM, Aschengrau A, Warram JH, Krolewski AS: Renal hyperfiltration and the development of microalbuminuria in type 1 diabetes. Diabetes Care 2009;32:889-893.

4 Jerums G, Premaratne E, Panagiotopoulos S, MacIsaac RJ: The clinical significance of hyperfiltration in diabetes. Diabetologia 2010; 53:2093-2104.

5 Ruggenenti P, Porrini EL, Gaspari F, Motterlini N, Cannata A, Carrara F, Cella C, Ferrari S, Stucchi N, Parvanova A, Iliev I, Dodesini AR, Trevisan R, Bossi A, Zaletel J, Remuzzi G; GFR Study Investigators: Glomerular hyperfiltration and renal disease progression in type 2 diabetes. Diabetes Care 2012;35:20612068.

6 Mogensen CE: Glomerular hyperfiltration in human diabetes. Diabetes Care 1994;17:770775.

7 Wiseman MJ, Saunders AJ, Keen H, Viberti G: Effect of blood glucose control on increased glomerular filtration rate and kidney size in insulin-dependent diabetes. N Engl J Med 1985;312:617-621.
8 Hansen KW, Mau Pedersen M, Christensen CK, Schmitz A, Christiansen JS, Mogensen CE: Normoalbuminuria ensures no reduction of renal function in type 1 (insulin-dependent) diabetic patients. J Intern Med 1992; 232:161-167.

9 Persson P, Hansell P, Palm F: Tubular reabsorption and diabetes-induced glomerular hyperfiltration. Acta Physiol (Oxf) 2010;200: 3-10.

10 Vallon V, Richter K, Blantz RC, Thomson S, Osswald H: Glomerular hyperfiltration in experimental diabetes mellitus: potential role of tubular reabsorption. J Am Soc Nephrol 1999; 10:2569-2576.

11 Osterby R, Gundersen HJ: Glomerular size and structure in diabetes mellitus. I. Early abnormalities. Diabetologia 1975;11:225-229.

12 Vallon V, Gerasimova M, Rose MA, Masuda T, Satriano J, Mayoux E, et al: SGLT2 inhibitor empagliflozin reduces renal growth and albuminuria in proportion to hyperglycemia and prevents glomerular hyperfiltration in diabetic Akita mice. Am J Physiol Renal Physiol 2014;306:F194-F204.

13 de Vries AP, Ruggenenti P, Ruan XZ, Praga M, Cruzado JM, Bajema IM, D'Agati VD, Lamb HJ, Pongrac Barlovic D, Hojs R, Abbate M, Rodriquez R, Mogensen CE, Porrini E; ERA-EDTA Working Group Diabesity: Fatty kidney: emerging role of ectopic lipid in obesity-related renal disease. Lancet Diabetes Endocrinol 2014;2:417-426.

14 Nelson RG, Bennett PH, Beck GJ, Tan M, Knowler WC, Mitch WE, Hirschman GH,
Myers BD: Development and progression of renal disease in Pima Indians with non-insulin-dependent diabetes mellitus. Diabetic Renal Disease Study Group. N Engl J Med 1996; 335:1636-1642.

15 Premaratne E, MacIsaac RJ, Tsalamandris C, Panagiotopoulos S, Smith T, Jerums G: Renal hyperfiltration in type 2 diabetes: effect of age-related decline in glomerular filtration rate. Diabetologia 2005;48:2486-2493.

16 Cherney DZ, Perkins BA, Soleymanlou N, Maione M, Lai V, Lee A, Fagan NM, Woerle HJ, Johansen OE, Broedl UC, von Eynatten $\mathrm{M}$ : Renal hemodynamic effect of sodium-glucose cotransporter 2 inhibition in patients with type 1 diabetes mellitus. Circulation 2014:129:587-597.

17 Gomez DM. Evaluation of renal resistances, with special reference to changes in essential hypertension. J Clin Invest 1951;30:11431155.

18 Skrtić M, Yang GK, Perkins BA, Soleymanlou N, Lytvyn Y, von Eynatten M, Woerle HJ, Johansen OE, Broedl UC, Hach T, Silverman M, Cherney DZ: Characterisation of glomerular haemodynamic responses to SGLT2 inhibition in patients with type 1 diabetes and renal hyperfiltration. Diabetologia 2014;57: 2599-2602.

19 Wanner C, Inzucchi SE, Lachin JM, Fitchett D, von Eynatten M, Mattheus M, Johansen OE, Woerle HJ, Broedl UC, Zinman B;EMPA-REG OUTCOME Investigators: Empagliflozin and progression of kidneydisease in type 2 diabetes. N Engl J Med 2016;375:323-334. 